\title{
Structural Change in the Near-Surface of a Silica Glass Block by Heat Treatment
}

\author{
Nobu KUZUU, James W. FOLEY* and Naoyoshi KAMISUGI** \\ Department of Applied Physics, Fukui University, 3-9-1, Bunkyo, Fukui-shi 910-8507 \\ *Weiss Scientific Glass Blowing Co., 14380, NW Scientific Park Dr., Portland, OR 97229, USA \\ **Yamaguchi Nippon Silica Glass, Co., Ltd., 4555, Kaisei-cho, Shinnanyo-shi, Yamaguchi 746-0006
}

\section{熱処理に伴うシリカガラス表面付近の構造変化}

\author{
葛生 伸・J.W. Foley*・神杉直良**
}

福井大学工学部応用物理学科, 910-8507 福井市文京 3-9-1

*Weiss Scientific Glass Blowing Co., 14380, NW Scientific Park Dr., Portland, OR 97229, USA

**山口日本石英硝子(株)，746-0006 新南陽市開成町 4555

\begin{abstract}
The effect of annealing on the distribution of $\mathrm{OH}$ content and defect structures in a disk shaped block of fused silica containing approximately $1500 \mathrm{ppm}$ of $\mathrm{OH}$ was investigated. Heating at $1160^{\circ} \mathrm{C}$ for $120 \mathrm{~h}$ reduced the $\mathrm{OH}$ content near surface by about $60 \mathrm{ppm}$, and absorption bands at $6.5,5.8,5.0$ and $4.8 \mathrm{eV}$ were induced near the side surface. The amount of the reduction of $\mathrm{OH}$ content near the top surface was about $45 \mathrm{ppm}$, and only the $6.5-\mathrm{eV}$ band was induced.

[Received August 20, 1997; Accepted February 20, 1998]
\end{abstract}

Key-words : Vitreous silica, Synthetic fused silica, Annealing, OH content, Defect structures

\section{Introduction}

Vitreous silica has high optical transmission in the ultraviolet (UV) region, and thermal expansion lower than that of multi-component optical glasses. ${ }^{1)}$ Therefore this material is used in fine optical components with UV light sources such as lenses in step-and-repeat projectors (stepper) with $\mathrm{KrF}$ excimer laser as the light source. Projection optics in the KrF-laser-stepper require extremely high homogeneity; the range of refractive index distribution is $\lesssim 1 \times 10^{-6}$ over the whole optical component and maximum birefringence is $\approx 1 \mathrm{~nm} / \mathrm{cm}$.

The refractive index of the silica glass is controlled by $\mathrm{OH}$ and $\mathrm{Cl}$ contents, and fictive temperature, the temperature at which the equilibrium structure is frozen in. ${ }^{2)}$ To control the fictive temperature, a silica glass block is usually annealed above the annealing point, i.e., 1100$1200^{\circ} \mathrm{C} .{ }^{1)}$ However, strain may sometimes be newly introduced during the annealing process. ${ }^{3)}$ Yamagata ${ }^{4), 5)}$ proposed a process to produce a silica glass block with high homogeneity, by which the refractive index distribution caused by the distribution of fictive temperature, $\mathrm{OH}$ and $\mathrm{Cl}$ contents distribution are balanced. However, he did not measure the fictive temperature directly and neglected the effect of strain induced by the annealing.

There are various kinds of vitreous silica. ${ }^{1)}$ Of them, type-III fused silica synthesized directly by hydrogen-oxygen flame hydrolysis of $\mathrm{SiCl}_{4}$, is used in UV optical components. This type of silica contains $500-1500 \mathrm{ppm}$ of $\mathrm{OH}$. With increasing $\mathrm{OH}$ content, the silica glass network becomes softer and various properties are changed. ${ }^{6)}$ For example, the silica becomes excimer-laser resistive, i.e., intensity of excimer-laser-induced absorption becomes negligibly small. This may be because of the softness of the glass network; with increasing softness the probability of bond breakage by irradiating with excimer-laser should become lower. Even if a bond breaks, the bond could rebind immediately after stopping the irradiation.

The effect of $\equiv \mathrm{SiOH}$ on the softness of the glass network is also supported by the fact that the Young's modulus was reduced by $\approx 4 \%$ when the $\mathrm{OH}$ content increased from 40 $\mathrm{ppm}$ to $1200 \mathrm{ppm} .^{7)}$ Additionally, viscosity at a high temperature decreases with increasing $\mathrm{OH}$ content. ${ }^{8)}$
These facts suggest that the structure of the glass network can be easily relaxed in materials containing higher $\mathrm{OH}$ concentrations. This is supported by the fact that in $\mathrm{OH}$-free silica, the relaxation time for Raman bands at 606 and 495 $\mathrm{cm}^{-1}$, caused by planer 3- and 4-fold rings, are about three orders longer than that of silica containing $1200 \mathrm{ppm}$ of OH. ${ }^{9)}$ As shown above, with increasing $\mathrm{OH}$ content, the glass network becomes softer and structural relaxation time becomes shorter.

Due to the existence of many dangling bonds formed by breaking the Si-O bonds, the glass surface must be energetically unstable. Thus the structure would change to stabilize the surface. In fact, Agarwal, et al. ${ }^{10)}$ suggested that the Si-O-Si bond angles near the surface are easier to relax than those in the bulk by comparing an IR-band at $2260 \mathrm{~cm}^{-1}$ by absorption and a band at $1120 \mathrm{~cm}^{-1}$ by reflection spectra. In an annealed block of silica glass, the structural change near the surface must affect the optical homogeneity. To study the effect of annealing on the structural change near surface, we analyzed the $\mathrm{OH}$ content distribution and the internal absorption of a silica glass block.

\section{Experimental procedure}

We used a type-III fused silica ${ }^{1)}$ synthesized directly by the hydrogen-oxygen flame hydrolysis of $\mathrm{SiCl}_{4}$. The $\mathrm{OH}$ content of the sample was $1400-1500 \mathrm{ppm}$ (see Fig. 1). The sample was cut from the center portion of an ingot that was about $20 \mathrm{~cm}$ in diameter and $60 \mathrm{~cm}$ in length. The sample was $15 \mathrm{~cm}$ in diameter and $4.6 \mathrm{~cm}$ in thickness, with center axis of the sample being the same as that of the ingot. The surfaces of the sample were ground by diamond tools; with the side surface finished by a cylindrical grinder with a \#80 diamond tool, and top and bottom faces are finished by a rotary grinder with a \#150 diamond tool. To measure the radial distribution of $\mathrm{OH}$ content before annealing, we cut samples near the top surface.

The sample was annealed using a Naber Therm N300/14 muffle furnace with the inner muffle dimensions $50 \mathrm{~cm}$ in width, $70 \mathrm{~cm}$ in height, and $60 \mathrm{~cm}$ in length. The sample was set in the center of the muffle. The temperature profile across the muffle is uniform to within $\pm 2^{\circ} \mathrm{C}$. The sample 

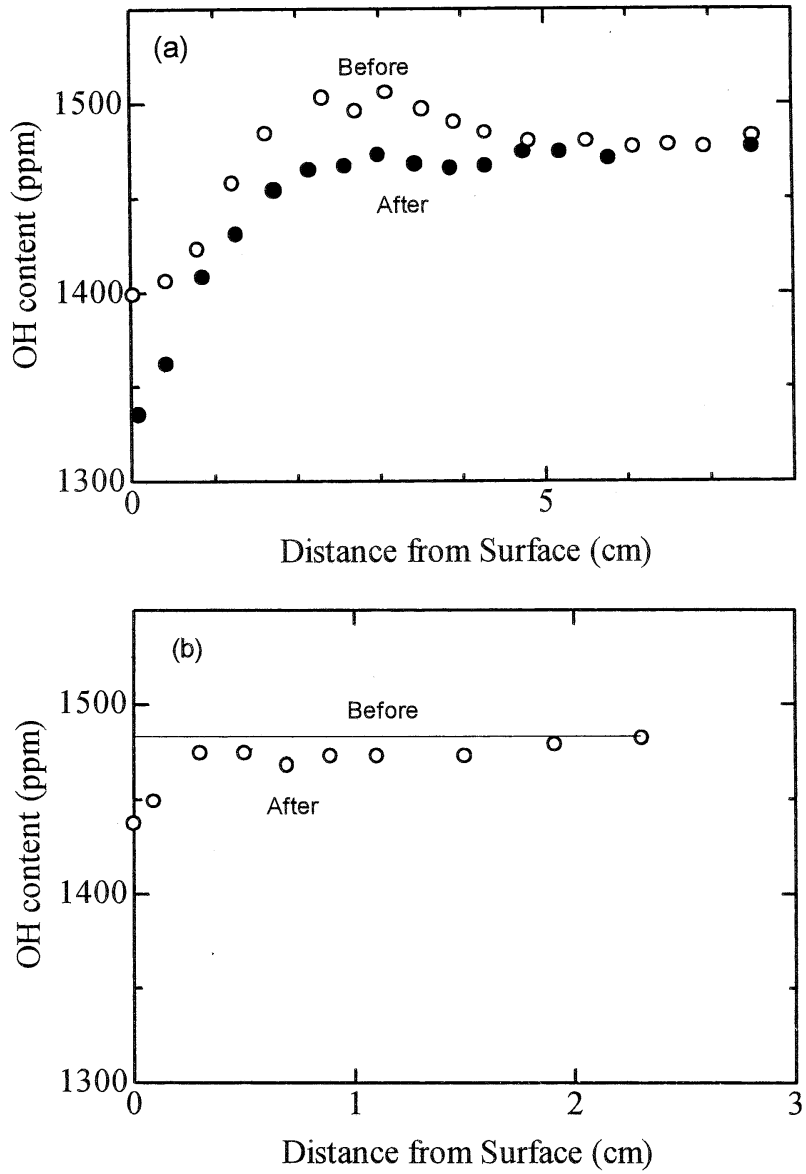

Fig 1. Distribution of $\mathrm{OH}$ content before and after annealing as a functions of distance from surface in (a) the radial and (b) the axial directions.

was heated at a rate of $30^{\circ} \mathrm{C} / \mathrm{h}$ up to $1160^{\circ} \mathrm{C}$, and held at this temperature for $120 \mathrm{~h}$. The sample was then cooled to $600^{\circ} \mathrm{C}$ at a rate of $6^{\circ} \mathrm{C} / \mathrm{h}$, and then cooled to room temperature uncontrolled. A sample with size of $1.5 \mathrm{~cm}$ in width and $1 \mathrm{~cm}$ in thickness was cut from the middle of the block along the radial direction.

Two opposite surfaces of the sample were polished and the $\mathrm{OH}$ content and internal absorption measured about every $2 \mathrm{~mm}$ along the samples radial direction. Another sample was cut along the center axis (referred to as the axial direction). $\mathrm{OH}$ content and absorption spectra were measured by a Shimadzu UV3101-PC spectrophotometer, which can measure the absorption at the wavelengths in 190-3200 nm. OH content was calculated from an absorption peak at $\left.2.2 \mu \mathrm{m},{ }^{1)}, 11\right)$ the extinction coefficient of which $1.72 \mathrm{l} / \mathrm{mol} \mathrm{cm}$ is obtained by comparing the absorption intensities of $0.7-\mathrm{mm}$ thick samples at $2.7 \mu \mathrm{m}$ (extinction coefficient being $77.5 \mathrm{l} / \mathrm{mol} \cdot \mathrm{cm}^{11)}$ ) and those of $10-\mathrm{mm}$ thick samples at $2.2 \mu \mathrm{m}$ for various $\mathrm{OH}$ amount. Using the internal absorption in the center of the before annealing sample as a reference, internal absorption after annealing was measured. Obtained spectra were analyzed by Gaussian peak decomposition described elsewhere. ${ }^{12)}$

\section{Results}

Figure 1 shows $\mathrm{OH}$ content distribution before and after annealing as a function of the distance from the surface in the radial direction (Fig 1 (a)) and the axial direction (Fig. 1 (b)). In the radial direction, $\mathrm{OH}$ content has a range of $\approx 100 \mathrm{ppm}$. Although there was no direct measurement of the axial $\mathrm{OH}$ content before annealing, $\mathrm{OH}$ content can be

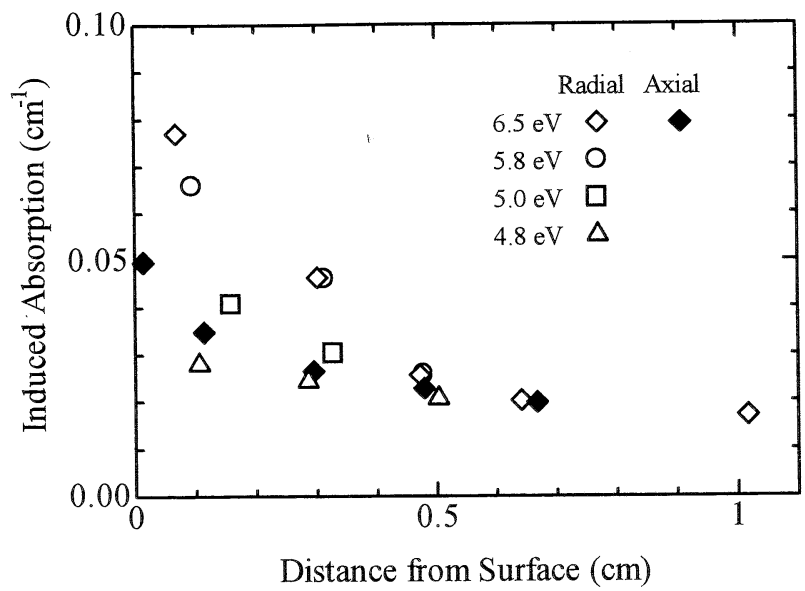

Fig. 2. Distribution of absorption bands produced by the annealing.

assumed as constant because the sample had been cut from the center portion of ingot with almost constant diameter.

In the radial direction, reduction of $\mathrm{OH}$ content was observed within $\approx 6 \mathrm{~cm}$ from the surface, and the amount of the reduction is $\$ 60 \mathrm{ppm}$. In the axial direction, the apparent change of $\mathrm{OH}$ content by annealing was observed only within $\approx 0.3 \mathrm{~cm}$ from the surface, and magnitude of the change in the surface is $\$ 45 \mathrm{ppm}$. The $\mathrm{OH}$ concentration of center of the sample before annealing is shown by horizontal solid line in the figure; this value is the $\mathrm{OH}$ content at the center axis. A small variation of $\mathrm{OH}$ content, $\approx 10 \mathrm{ppm}$, is observed within $\approx 0.3 \mathrm{~cm}$ from the surface in the axial direction. This variation may not be significant but just the error of the observation.

In the previous papers, one of the present authors and coworkers showed the X-ray, ${ }^{12)}$ ArF excimer laser, ${ }^{6), 13)}$ and $\gamma$-ray ${ }^{14)}$ induced absorption can be fitted by the Gaussian absorption bands peaking at $6.5,5.8,5.4,5.0$ and $4.8 \mathrm{eV}$. Absorption bands produced by annealing can also be fitted by the same set of the absorption bands with the same peak positions and full width at half maxima (FWHM's). Figure 2 shows the distribution of absorption components using the same peak positions and FWHM's as in Ref. 12. Differences between the radial and the axial distributions are also observed as in the case of the $\mathrm{OH}$ content distribution. In the radial direction, absorption bands at 6.5, 5.8, 5.0 and $4.8 \mathrm{eV}$ were observed. In the axial direction, however, only the $6.5-\mathrm{eV}$ band was observed, its intensity is weaker than the $6.5-\mathrm{eV}$ band of the radial direction. The absorption intensity is strongest at the surface and observed within $\approx 0.5 \mathrm{~cm}$ from the surface except the $6.5 \mathrm{-eV}$ band, which was induced further in from the surface.

\section{Discussion}

Reduction of $\mathrm{OH}$ content near surface should mainly caused by,

$$
\equiv \mathrm{Si}-\mathrm{OH} \mathrm{HO}-\mathrm{Si} \equiv \longrightarrow \equiv \mathrm{Si}-\mathrm{O}-\mathrm{Si} \equiv+\mathrm{H}_{2} \mathrm{O}
$$

In a previous paper, ${ }^{11)}$ one of the present authors and coworkers proposed that the existence of $\equiv \mathrm{Si}-\mathrm{H} \mathrm{HO}-\mathrm{Si} \equiv$ structures in type-III fused silica synthesized under reducing conditions. From this structure, $\mathrm{OH}$ content can be reduced as,

$$
\equiv \mathrm{Si}-\mathrm{H} \mathrm{HO}-\mathrm{Si} \equiv \longrightarrow \equiv \mathrm{Si}-\mathrm{O}-\mathrm{Si} \equiv+\mathrm{H}_{2}
$$

The origin of the $6.5-\mathrm{eV}$ band is not known, but it could be related to metallic impurities.

The $5.8-\mathrm{eV}$ band is ascribed to the $E^{\prime}$ center $(\equiv \mathrm{Si} \bullet$ ). The $5.0-\mathrm{eV}$ band is $B_{2} \alpha$ band $^{15}$ ) ascribed to oxygen deficient center $(\mathrm{ODC}$; $\equiv \mathrm{Si} \cdots \mathrm{Si} \equiv)$. The ODC must be produced by 
breaking $\mathrm{Si}-\mathrm{O}-\mathrm{Si}$ bond by the stress produced by the shrinkage of the glass network accompanied with the reduction of water as described by Eq. (1). Part of the ODC might changed into the $E^{\prime}$ center. ${ }^{15)}$ In fact $\mathrm{OH}$ - and $\mathrm{Cl}$-free synthetic fused silica have a weak $5.8-\mathrm{eV}$ band accompanied with the 5.0-eV band.6) There is another type of 5.0$\mathrm{eV}$ band called the $B_{2} \beta$ band. ${ }^{15)}$ Although these two types of bands can be distinguished by their emission spectra, luminescence caused by impurity contamination during the annealing could interfere with the distinction.

The $4.8-\mathrm{eV}$ band is an oxygen related center and a number of models, such as nonbridging oxygen hole center $(\mathrm{NBOHC} ; \equiv \mathrm{Si}-\mathrm{O} \bullet$ ), peroxyradicals $(\mathrm{PR} ; \equiv \mathrm{Si}-\mathrm{OO} \bullet$ ) and $\mathrm{O}_{3}$, are proposed. ${ }^{15)}$ NBOHCs are produced by breaking $\mathrm{Si}-$ $\mathrm{O}-\mathrm{Si}$ bonds as,

$$
\equiv \mathrm{Si}-\mathrm{O}-\mathrm{Si} \equiv \longrightarrow \equiv \mathrm{Si} \cdot \cdot \mathrm{O}-\mathrm{Si} \equiv
$$

Oxygen atoms will be produced by,

$$
\equiv \mathrm{Si}-\mathrm{O}-\mathrm{Si} \equiv \longrightarrow \equiv \mathrm{Si} \cdots \mathrm{Si} \equiv+\mathrm{O}
$$

which can form $\mathrm{O}_{2}$ and/or $\mathrm{O}_{3}$ molecules by reacting with each other. By reacting oxygen atoms with $E^{\prime}$ centers, $\mathrm{NBOHCs}$ will be formed as,

$$
\equiv \mathrm{Si} \bullet+\mathrm{O} \longrightarrow \equiv \mathrm{Si}-\mathrm{O} \text {. }
$$

and by reacting oxygen molecules with $E^{\prime}$ centers, PR's will be formed as

$$
\equiv \mathrm{Si} \bullet+\mathrm{O}_{2} \longrightarrow \equiv \mathrm{Si}-\mathrm{OO} \bullet
$$

Another probable origin of the $4.8-\mathrm{eV}$ band is $\mathrm{H}_{2} \mathrm{O}$ molecules bound to $\equiv \mathrm{SiOH}$ by hydrogen bond which could cause the $4.8-\mathrm{eV}$ band accompanied with the $5.8-\mathrm{eV}$ band. ${ }^{16)}$

The change in $\mathrm{OH}$ content and creation of absorption bands show that the damage in the radial direction is stronger than that in the axial direction. A probable origin of this difference is that the difference in curvatures between the side and the top surfaces; the manner to stabilize the surface structures could be strongly dependent on the surface curvature. Another probable origin is the difference in the finishing conditions; the top surface was finished with a rotary grinder with a $\# 150$ diamond tool and the side surface was finished with a cylindrical grinder with a \#80 diamond tool. From the present data, however, we cannot determine which is main the factor to produce the changes to $\mathrm{OH}$ content and the absorption bands.

\section{Conclusions}

We have investigated the effect of the annealing on the structure near surface of a silica glass block. By monitoring the $\mathrm{OH}$ content distribution and induced absorption, it was found that the $\mathrm{OH}$ content is reduced near the surface and absorption bands at 6.5, 5.8, 5.0 and $4.8 \mathrm{eV}$ are induced. In the view point of developing a high homogeneity optical material, we have to monitor the change of refractive index distribution and birefringence in addition to the $\mathrm{OH}$ content distribution and induced absorption. We need further studies on this aspect.

Silica glass is constructed of a network of connected $\mathrm{SiO}_{4}$ tetrahedra by covalent bonds. Since many defect structures formed by the breaking of Si-O bonds should exist on the surface, surface free energy should be higher than that of multicomponent glasses in which modifier ions would stabilize the surface. During annealing of a fused silica block, the surface structure would be changed to reduce the surface free energy of the silica glass.

Since the silica glass is an amorphous material, direct comprehension of this structure is difficult. Studies on the change of the near-surface structure would be fruitful not only to understanding engineering problems such as cutting, grinding and polishing, but also scientific interest that could be clarify the silica glass structure.

Acknowledgement This study was partly supported by Grantin-Aid for Scientific Research from the Ministry of Education, Science, Sports and Culture, Japan (No. 09650730)

\section{References}

1) N. Kuzuu, "Sekiei Garasu no Sekai (Introduction to Silica Glass Science and Technology)," Kogyo Chosakai (1995) pp. 103-39 (in Japanese).

2) R. Brückner, J. Non-Cryst. Solids, 5, 123-75 (1970).

3) W. Primak, Phys. Chem. Glasses, 24, 8-18 (1983).

4) S. Yamagata, J. Ceram. Soc. Japan, 100, 337-41 (1992).

5) S. Yamagata, Mineral. J., 16, 1-15 (1992).

6) N. Kuzuu, T. Taga and N. Kamisugi, J. Appl. Phys., 81, 8011-17 (1997).

7) H. Kobayashi, T. Kosugi and Y. Kogure, Physica B, 219 \& 220, 276-79 (1996).

8) Y. Kikuchi, H. Sudo and N. Kuzuu, J. Ceram. Soc. Japan, 105, 645-49 (1997).

9) F. J. Galeener, J. Non-Cryst. Solids, 71, 373-86 (1985).

10) A. Agarwal, K. M. Davis and M. Tomozawa, J. Non-Cryst. Solids, 185, 191-98 (1995).

11) N. Kuzuu, Y. Komatsu and M. Murahara, Phys. Rev. B, 44, 9265-70 (1991).

12) N. Kuzuu, J. Non-Cryst. Solids, 179, 170-78 (1994).

13) N. Kuzuu and M. Murahara, Phys. Rev. B, 52, 3241-47 (1995).

14) Y. Kawaguchi and N. Kuzuu, J. Appl. Phys., 80, 5633-38 (1996).

15) D. L. Griscom, J. Ceram. Soc. Japan, 99, 923-42 (1991).

16) N. Kuzuu, Y. Komatsu and M. Murahara, Phys. Rev. B, 45, 2050-54 (1992). 